\title{
RESEARCH
}

Open Access

\section{Dietary fructose-induced gut dysbiosis promotes mouse hippocampal neuroinflammation: a benefit of short-chain fatty acids}

Jian-Mei Li ${ }^{*}{ }^{+}$, Rong Y Yu${ }^{\dagger}$, Li-Ping Zhang, Shi-Yu Wen, Shui-Juan Wang, Xiao-Yang Zhang, Qiang Xu and Ling-Dong Kong*

\begin{abstract}
Background: Western-style diets arouse neuroinflammation and impair emotional and cognitive behavior in humans and animals. Our previous study showed that a high-fructose diet caused the hippocampal neuroinflammatory response and neuronal loss in animals, but the underlying mechanisms remained elusive. Here, alterations in the gut microbiota and intestinal epithelial barrier were investigated as the causes of hippocampal neuroinflammation induced by high-fructose diet.

Results: A high-fructose diet caused the hippocampal neuroinflammatory response, reactive gliosis, and neuronal loss in C57BL/6N mice. Depletion of the gut microbiota using broad-spectrum antibiotics suppressed the hippocampal neuroinflammatory response in fructose-fed mice, but these animals still exhibited neuronal loss. Gut microbiota compositional alteration, short-chain fatty acids (SCFAs) reduction, intestinal epithelial barrier impairment, NOD-like receptor family pyrin domain-containing 6 (NLRP6) inflammasome dysfunction, high levels of serum endotoxin, and FITC-dextran were observed in fructose-fed mice. Of note, SCFAs, as well as pioglitazone (a selective peroxisome proliferator-activated receptor gamma (PPAR- $\gamma$ ) agonist), shaped the gut microbiota and ameliorated intestinal epithelial barrier impairment and NLRP6 inflammasome dysfunction in fructose-fed mice. Moreover, SCFAs-mediated NLRP6 inflammasome activation was inhibited by histamine (a bacterial metabolite) in ex vivo colonic explants and suppressed in murine CT26 colon carcinoma cells transfected with NLRP6 siRNA. However, pioglitazone and GW9662 (a PPAR-y antagonist) exerted no impact on SCFAs-mediated NLRP6 inflammasome activation in ex vivo colonic explants, suggesting that SCFAs may stimulate NLRP6 inflammasome independently of PPAR- $\gamma$ activation. SCFAs and pioglitazone prevented fructose-induced hippocampal neuroinflammatory response and neuronal loss in mice. Additionally, SCFAs activated colonic NLRP6 inflammasome and increased DCX ${ }^{+}$newborn neurons in the hippocampal DG of control mice.

\footnotetext{
* Correspondence: lijm@nju.edu.cn; kongld@nju.edu.cn

${ }^{\dagger} J i a n-M e i$ Li and Rong Yu contributed equally to this work.

State Key Laboratory of Pharmaceutical Biotechnology, School of Life

Sciences, Nanjing University, Nanjing 210023, People's Republic of China
}

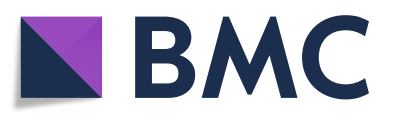

(c) The Author(s). 2019 Open Access This article is distributed under the terms of the Creative Commons Attribution 4.0 International License (http://creativecommons.org/licenses/by/4.0/), which permits unrestricted use, distribution, and reproduction in any medium, provided you give appropriate credit to the original author(s) and the source, provide a link to the Creative Commons license, and indicate if changes were made. The Creative Commons Public Domain Dedication waiver (http://creativecommons.org/publicdomain/zero/1.0/) applies to the data made available in this article, unless otherwise stated. 


\begin{abstract}
(Continued from previous page)
Conclusions: Our findings reveal that gut dysbiosis is a critical factor for a high-fructose diet-induced hippocampal neuroinflammation in C57BL/6N mice possibly mediated by impairing intestinal epithelial barrier. Mechanistically, the defective colonic NLRP6 inflammasome is responsible for intestinal epithelial barrier impairment. SCFAs can stimulate NLRP6 inflammasome and ameliorate the impairment of intestinal epithelial barrier, resulting in the protection against a high-fructose diet-induced hippocampal neuroinflammation and neuronal loss. This study addresses a gap in the understanding of neuronal injury associated with Western-style diets. A new intervention strategy for reducing the risk of neurodegenerative diseases through SCFAs supplementation or dietary fiber consumption is emphasized.
\end{abstract}

Keywords: Gut dysbiosis, Neuroinflammation, Neuronal loss, Short-chain fatty acids, NLRP6 inflammasome

\section{Background}

Neuroinflammation is a hallmark of neurodegenerative diseases associated with Western-style diets, including high-calorie diets rich in processed sugars (fructose or sucrose) and fats [1-4]. The gut microbiota has been reported to modulate adult hippocampal neurogenesis and neurological function by controlling the maturation and function of microglia in germ-free and antibiotic-treated specific pathogen-free (SPF) mice $[5,6]$, indicating that the alteration in the gut microbiota (gut dysbiosis) may be major event initiating neuroinflammation and subsequent neuronal injury $[5,7,8]$.

The intestinal epithelial barrier prevents the entry of exterior antigens from the gut lumen into the host, which may exacerbate both local and systemic immune responses $[9,10]$. The front line of this barrier is composed of epithelial cells and apical junctional complexes encompassing tight junction (TJ) proteins and adherens junctions between adjacent epithelial cells [11, 12]. NOD-like receptor family pyrin domain-containing 6 (NLRP6) inflammasome, an intracellular innate immune sensor, orchestrates colonic mucosal defense against bacterial pathogens [13-15]. Commensal microbes and their metabolites are crucial for the integrity of the intestinal epithelial barrier [16-18], possibly regulating the NLRP6 inflammasome signaling to maintain intestinal microenvironment homeostasis [19]. Of note, some dietary ingredients, such as fructose, fat, and heme, have been reported to alter the gut microbiota and disrupt intestinal epithelial barrier integrity in mice [20-23]. In particular, diets rich in fructose cause gut dysbiosis, leading to microbial metabolite disorder and intestinal epithelial barrier damage in rodents [20, 23, 24]. Dietary fructose also disrupts hippocampal energy homeostasis, induces neuroinflammation and neuronal injury, and impairs spatial learning and memory in rodents [25-27]. However, it is unclear whether dietary fructose-induced gut dysbiosis promotes hippocampal neuroinflammation through the impairment of intestinal epithelial barrier with the NLRP6 inflammasome dysfunction.

A diet rich in fiber ameliorates intestinal epithelial barrier defect and inflammation in dextran sodium sulfate
(DSS)-induced colitic mice [28] and protects mouse lung from allergic inflammation [29]. Ingested dietary fibers are readily fermented by colonic bacteria to produce organic acids, including short-chain fatty acids (SCFAs). Treatment with SCFAs attenuates a high-fat dietinduced change in the gut microbiota and intestinal epithelial barrier integrity in C57BL/6 mice, possibly through the inhibition of systemic inflammation [30,31]. SCFAs may have the ability to modulate the maturation and function of microglia in the brain, suggesting the potential benefits of gut microbiota-derived SCFAs in protecting against neuroinflammatory process $[6,32]$. Neuroprotective effects of SCFAs have also been demonstrated in animal models of neurodegenerative disorders $[32,33]$, but there is a need for more evidence.

In this study, we found that dietary fructose-driven gut dysbiosis caused intestinal epithelial barrier impairment associated with the occurrence of hippocampal neuroinflammation in C57BL/6N mice. Peroxisome proliferatoractivated receptor gamma (PPAR- $\gamma$ ) is a butyrate sensor in the colonic lumen [34]. Microbiota-activated PPAR- $\gamma$ signaling has been reported to prevent dysbiotic expansion of pathogenic bacteria by driving the energy metabolism of colonic epithelial cells [35]. We also highlighted the key molecular mechanisms by which SCFAs, as well as pioglitazone (a PPAR $-\gamma$ agonist), repaired intestinal epithelial barrier damage by activating the NLRP6 inflammasome, possibly contributing to the inhibition of hippocampal neuroinflammatory response and neuronal loss in fructose-fed mice.

\section{Results}

\section{Depletion of the gut microbiota inhibits hippocampal} neuroinflammation in fructose-fed mice

A hippocampal neuroinflammatory response, characterized by significant upregulation of interleukin-1 beta (IL$1 \beta$ ), tumor necrosis factor alpha (TNF- $\alpha$ ), and IL-6 mRNA levels, was observed in C57BL/6N mice fed a high-fructose diet for eight weeks (Fig. 1a). Immunofluorescence staining showed that the numbers of Iba- $1^{+}$ microglia were significantly increased in the whole hippocampus of high-fructose diet-fed mice compared 

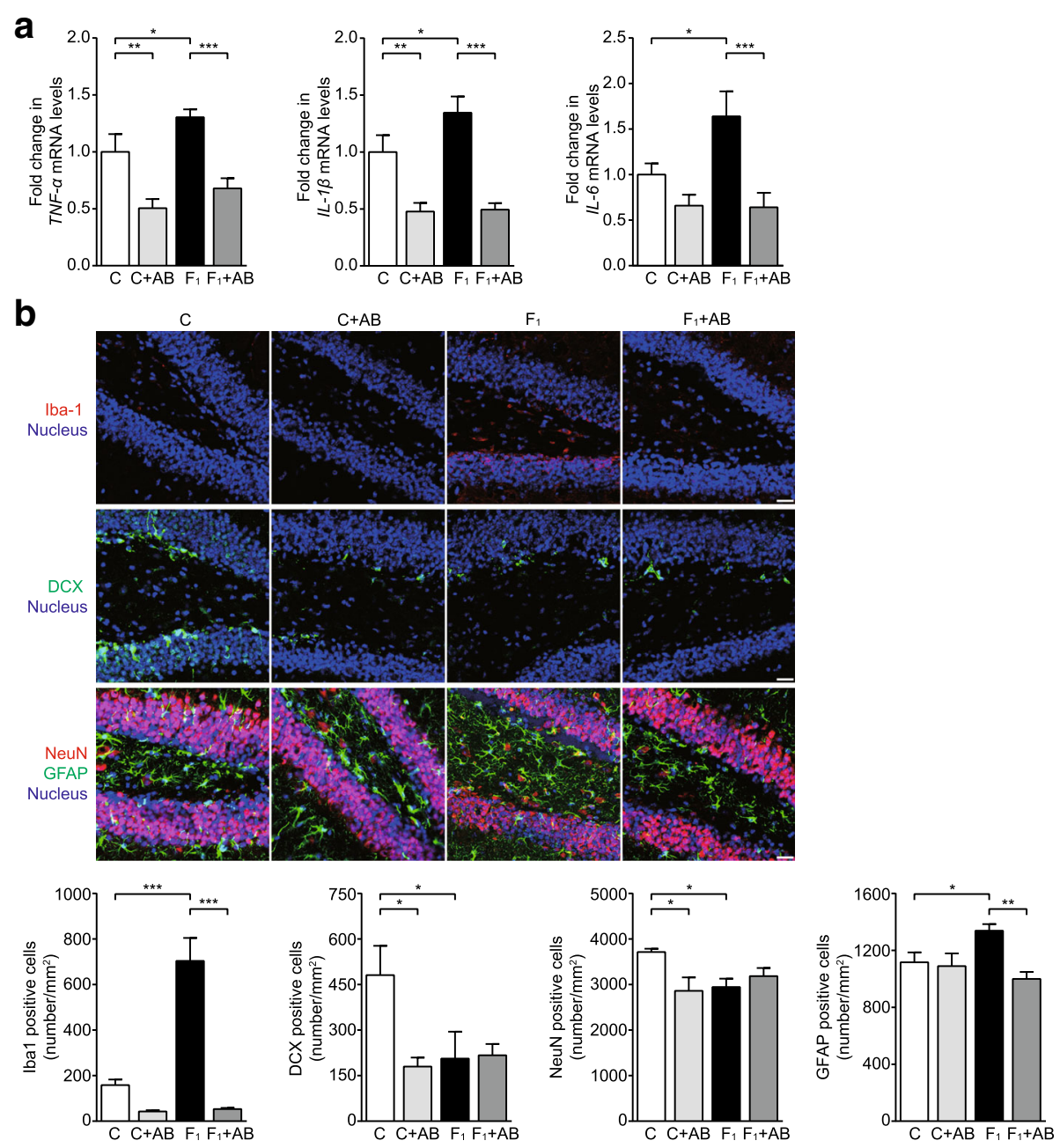

Fig. 1 Depletion of the gut microbiota inhibits hippocampal neuroinflammation but fails to reverse the neuronal loss in high-fructose diet-fed C57BL/6N mice. a TNF-a, IL-1 $\beta$, and IL-6 mRNA levels in the hippocampus $(n=6)$. b Representative immunofluorescence images and quantitative analysis of Iba-1-positive cells (red), DCX-positive cells (green), NeuN-positive cells (red), and GFAP-positive cells (green) with nuclear counterstain (blue) in the hippocampal DG. Bars, $25 \mu \mathrm{m}$. Data are presented as mean \pm SEM. ${ }^{*} p<0.05,{ }^{* *} p<0.01,{ }^{* *} p<0.001$ indicate significant difference. C control group, $F_{1}$ eight-week fructose-fed group, AB antibiotics-treated group

with standard diet-fed animals (Fig. $1 \mathrm{~b}$ and Additional file 1: Figure S1a). The numbers of $\mathrm{NeuN}^{+}$neurons and doublecortin $(\mathrm{DCX})^{+}$newborn neurons were significantly reduced, whereas of $\mathrm{GFAP}^{+}$astrocytes were increased, in the hippocampal dentate gyrus (DG) (Fig. 1b) but not in the cornu ammonis 1 (CA1) and CA3 areas (Additional file 1: Figure S1b) in fructose-fed mice. These results confirm that a high-fructose diet induces hippocampal neuroinflammatory response and neuronal loss in C57BL/6N mice.

To determine whether dietary fructose-induced hippocampal neuroinflammatory response required continuous input from the resident microbes, half of the control and fructose-fed animals were orally treated with broadspectrum antibiotics (including ampicillin, vancomycin, neomycin, metronidazole, and amphotericin B) during the last four weeks of the experiment. Antibiotic treatment severely reduced microbial abundance and diversity, resulting in a blank microbial composition profile in both the control and fructose-fed groups (Additional file 1: Figure S1c and d) . In control mice, antibiotics caused significant reduction in IL-1 $\beta$ and TNF- $\alpha$ mRNA levels and a decreasing trend in IL-6 mRNA levels (Fig. 1a) and the numbers of Iba- $1^{+}$ microglia in the whole hippocampus (Fig. 1b and Additional file 1: Figure S1a). Notably, in fructose-fed mice, antibiotics inhibited the upregulation of hippocampal IL-1 $\beta$, TNF- $\alpha$, and IL- 6 mRNA levels and the increase in the numbers of Iba- $1^{+}$microglia (Fig. 1a, b and Additional file 1: Figure S1a). Moreover, antibiotics significantly decreased the numbers of $\mathrm{NeuN}^{+}$neurons and $\mathrm{DCX}^{+}$newborn neurons without affecting the numbers of $\mathrm{GFAP}^{+}$astrocytes in the hippocampal DG in control mice (Fig. 1b). Of note, 
antibiotics suppressed the increase in the numbers of $\mathrm{GFAP}^{+}$astrocytes but failed to attenuate the fructoseinduced decrease in the numbers of $\mathrm{NeuN}^{+}$neurons and $\mathrm{DCX}^{+}$newborn neurons (Fig. 1b) in mice. There were no significant differences in the numbers of $\mathrm{GFAP}^{+}$astrocytes in the hippocampal $\mathrm{CA} 1$ and $\mathrm{CA} 3$ regions among the groups (Additional file 1: Figure S1b). These results indicate that gut dysbiosis plays an important role in a high-fructose diet-induced hippocampal neuroinflammatory response in C57BL/6N mice.

\section{A high-fructose diet induces gut dysbiosis, SCFAs reduction, and intestinal epithelial barrier impairment in C57BL/6N mice}

To assess the influence of dietary fructose on the gut microbiota in mice, the fecal microbiota was analyzed using $16 \mathrm{~S}$ rRNA gene amplicon sequencing. A highfructose diet feeding for eight weeks changed the microbial community structure but had no effect on microbial alpha-diversity in mice (Fig. 2a and b, Additional file 1: Figure S2a). The abundance of Bacteroidetes was significantly decreased and Proteobacteria was significantly increased in fructose-fed mice. Moreover, these animals showed an increasing trend in Firmicutes (Fig. 2c). Fructose feeding also led to marked enrichment of the pathogenic bacterial taxa Deferribacteraceae (Mucispirillum) and Helicobacteraceae (Helicobacter) in mice (Additional file 1: Figure S2b). Although main SCFAsproducing bacteria, such as Lachnospiraceae and Ruminococcaceae, were highly enriched in fructose-fed mice (Additional file 1: Figure S2c), the fecal concentrations of acetate, propionate, butyrate, and total SCFAs were significantly lower in fructose-fed mice than in control group (Fig. 2d). Antibiotics reduced the fecal concentrations of acetate, propionate, butyrate, and total SCFAs in both control and fructose-fed animals (Fig. 2d).

A high-fructose diet feeding caused histological changes characterized by thinning of the intestinal mucosa, epithelium, and muscularis mucosae; loss of crypts and glands, edema of the lamina propria; and discrete infiltration of inflammatory cells in mice (Fig. 2e and Additional file 1: Figure S2d). Consistently, serum endotoxin and FITCdextran levels were increased significantly in fructose-fed mice compared with control animals (Fig. 2f). Electron microscopy also showed short and sparse microvilli, severe mitochondrial swelling, and vacuole change in epithelial cells as well as loss of $\mathrm{TJ}$ domains, irregular gaps, and increased distance between adjacent epithelial cells in the colon and distal ileum in fructose-fed mice (Fig. $2 \mathrm{~g}$ and Additional file 1: Figure S2f). Moreover, colonic mucin 2 (Muc2), occludin, and zonula occludens-1 (ZO1) protein levels were downregulated significantly in fructose-fed mice (Fig. 2h). After antibiotic treatment, both control and fructose-fed mice showed intestinal histological changes, but intestinal epithelial cells were arranged tightly and in an orderly manner with perfect mitochondrial structure (Fig. 2e, g, Additional file 1: Figure S2d and f). In addition, fructose-fed mice showed a significant decrease in serum endotoxin levels after antibiotic treatment (Additional file 1: Figure S2e), although there was still significantly decreased colonic Muc2, occludin, and ZO-1 expression in the fructose-fed group compared with the control group (Fig. 2h). In control mice, antibiotics caused a significant decrease in colonic Muc2 expression and a trend toward a decrease in colonic occludin and ZO-1 expression (Fig. 2h). Together, these results indicate that a high-fructose diet induces gut dysbiosis, reduces SCFAs levels, and causes intestinal epithelial barrier impairment in C57BL/6N mice.

SCFAs and pioglitazone partially shape gut dysbiosis and ameliorate intestinal epithelial barrier impairment in fructose-fed mice

Next, we tested whether oral administration of SCFAs and a PPAR- $\gamma$ agonist prevented dietary fructose-induced intestinal epithelial barrier impairment in C57BL/6N mice. Although the microbial structures in fructose-fed mice were still different from those in control mice, to some extent, SCFAs and pioglitazone reduced the enriched diversity in fructose-fed mice (Fig. 3a, b). SCFAs and pioglitazone improved bacterial composition and structure (Fig. 3c and Additional file 1: Figure S3a) and prevented the increase in the abundance of the pathogenic bacterial taxon Deferribacteraceae (Mucispirillum), but the former failed to decrease the abundance of Helicobacteraceae (Helicobacter) (Additional file 1: Figure S3b) in fructose-fed mice. In addition, SCFAs and pioglitazone alleviated the pathological changes in the intestinal mucosa, epithelium, and muscularis mucosae and prevented substructural damage to epithelial cells in fructose-fed mice (Fig. 3d, f, Additional file 1: Figure S3c and d). Consistently, the increase in blood endotoxin levels and the reduction in Muc2, ZO-1, and occludin protein expression in fructose-fed mice were also reversed by SCFAs and pioglitazone (Fig. 3e, g). SCFAs-treated normal mice showed no significant change in intestinal structure or colonic occludin expression (Additional file 1: Figure S3e and f). These results support the notion that SCFAs and PPAR$\gamma$ agonist pioglitazone shaped gut dysbiosis and prevented intestinal epithelial barrier impairment in fructose-fed mice.

\section{Fructose-fed mice exhibit a defect in colonic NLRP6 inflammasome, which is ameliorated by SCFAs and pioglitazone}

Notably, the abnormal production of colonic interferon gamma (IFN- $\gamma$ ), TNF- $\alpha$, and IL-10 further demonstrated a gut immune imbalance in fructose-fed mice, which were ameliorated by SCFAs and pioglitazone (Additional file 1: Figure S4a). Colonic NLRP6 and cleaved 

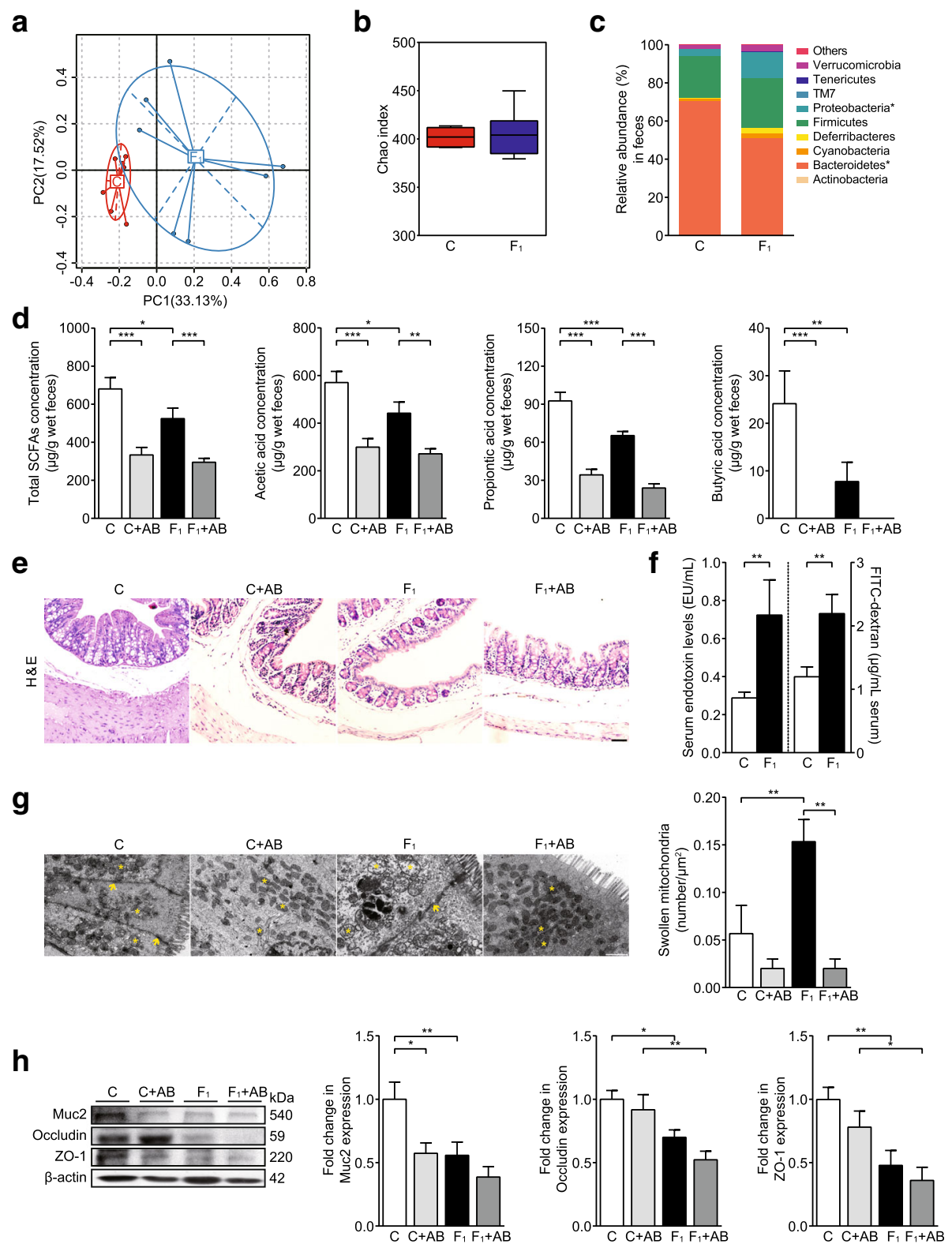

Fig. 2 A high-fructose diet induces gut dysbiosis, SCFAs reduction, and colonic epithelial barrier impairment in C57BL/6N mice. a PCoA based on the relative abundance of bacterial OTU, $\mathbf{b}$ Chao 1 diversity indexes of bacterial community, $\mathbf{c}$ relative abundance of bacterial phyla, and $\mathbf{d}$ SCFA concentrations in fecal samples $(n=7)$. e Colon histopathology (bars, $50 \mu \mathrm{m})$. $\mathbf{f}$ Endotoxin and FITC-dextran levels in serum $(n=8)$. $\mathbf{g}$ Representative transmission electron micrographs of colon epithelial cells (bars, $1 \mu \mathrm{m}$ ). Arrows indicate gap junctions between two neighbored cells. Asterisks indicate the mitochondria in epithelial cells. $\mathbf{h}$ Immunoblot analysis for protein levels of Muc2, occludin, and ZO-1 in colon tissue $(n=6)$. Quantification: band intensity normalized to $\beta$-actin. Data are presented as mean \pm SEM. ${ }^{*} p<0.05,{ }^{* *} p<0.01,{ }^{* *} p<0.001$ indicate significant difference. $C$ control group, $F_{1}$ eight-week fructose-fed group, $A B$ antibiotics-treated group

caspase-1 P10 levels were significantly reduced, and colonic IL-18 secretion was decreased in fructose-fed mice (Fig. 4a). In the control group, antibiotics significantly decreased NLRP6 and cleaved caspase-1 P10 protein levels but showed no effect on colonic IL-18 secretion (Fig. 4a). In fructose-fed mice, antibiotics reversed the decrease in colonic IL-18 secretion and further suppressed colonic NLRP6 expression (Fig. 4a). SCFAs or pioglitazone also prevented the reduction in colonic NLRP6 levels and caspase- 1 activation in fructose-fed mice, resulting in the recovery of IL-18 production (Fig. 4b). In comparison to that in control mice, colonic NLRP3 expression was not altered in fructose-fed mice treated with SCFAs and pioglitazone but was decreased significantly in antibiotic-treated control and fructosefed mice (Fig. 4a, b). Moreover, colonic expression of 


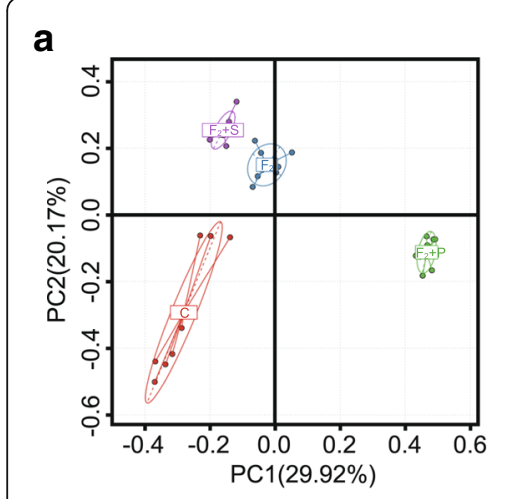

d

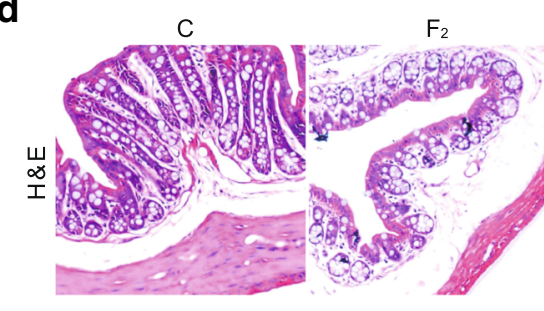

b
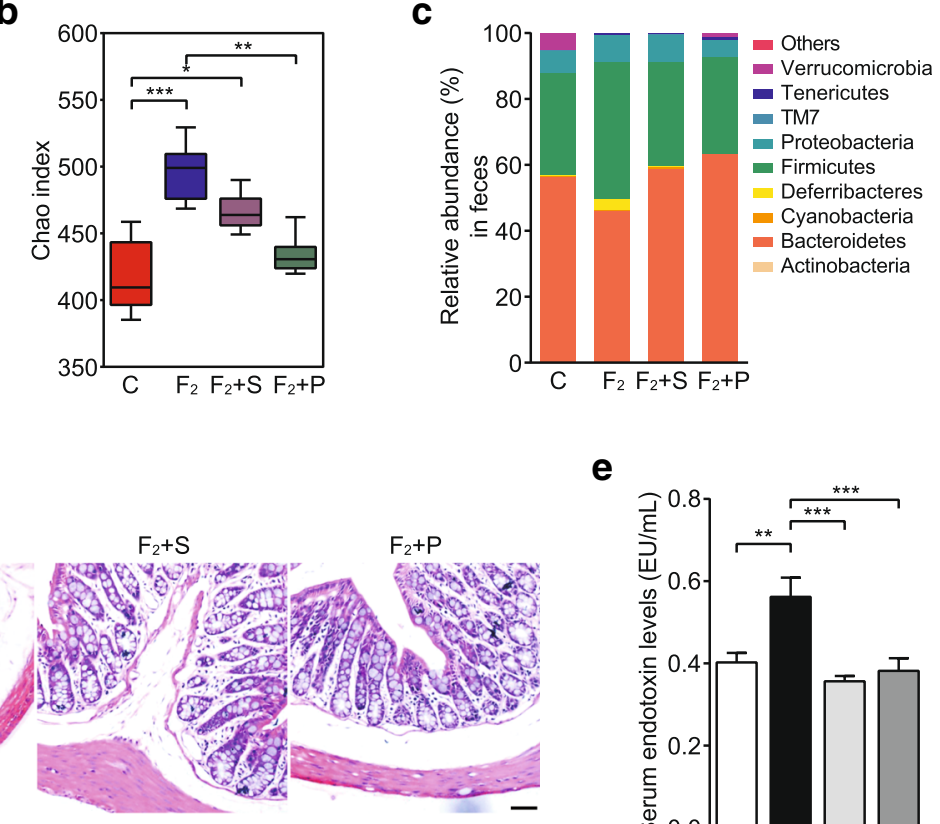

e

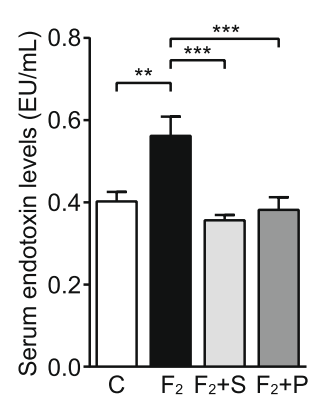

$\mathbf{f}$

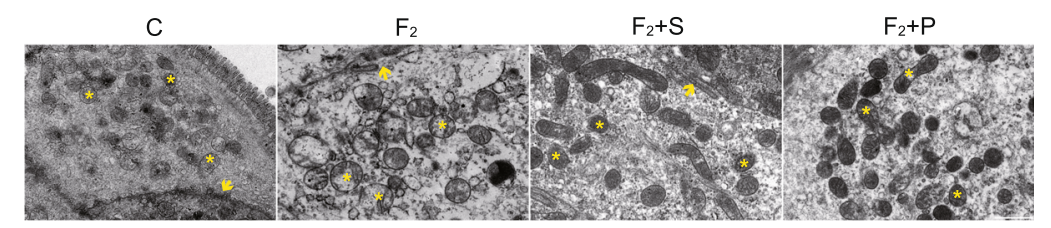

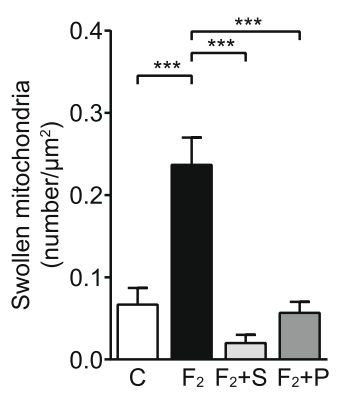

$\mathbf{g}$

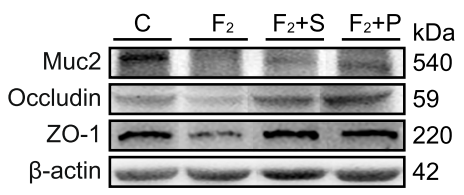

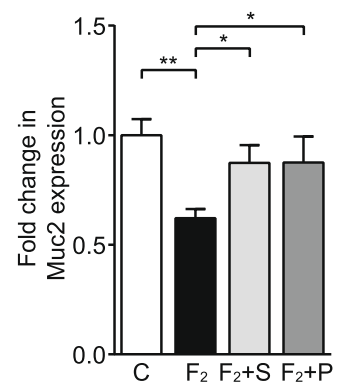
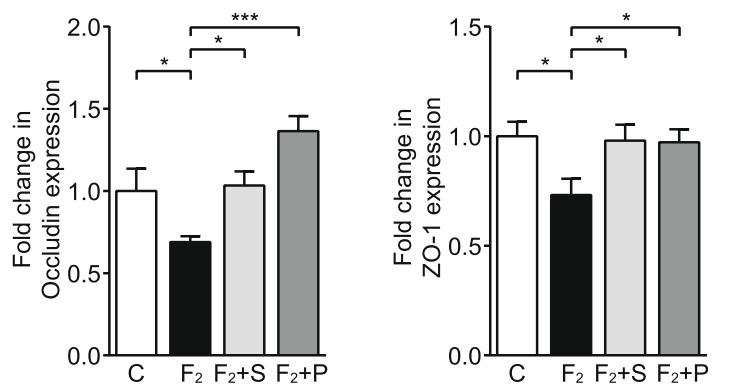

Fig. 3 SCFAs and pioglitazone shape gut dysbiosis and improve intestinal epithelial barrier impairment in high-fructose diet-fed C57BL/6N mice a PCoA based on the relative abundance of bacterial OTU, $\mathbf{b}$ Chaol diversity indexes of bacterial community, and $\mathbf{c}$ relative abundance of bacterial phyla in fecal samples $(n=7)$. $\mathbf{d}$ Colon histopathology (bars, $50 \mu \mathrm{m})$. e Endotoxin levels in serum $(n=8)$. $\mathbf{f}$ Representative transmission electron micrographs of colonic epithelial cells (bars, $1 \mu \mathrm{m}$ ). Arrows indicate gap junctions between two neighbored cells. Asterisks indicate the mitochondria in epithelial cells. $\mathbf{g}$ Immunoblot analysis for protein levels of Muc2, occludin, and ZO-1 in colon tissue ( $n=6)$. Quantification: band intensity normalized to $\beta$-actin. Data are presented as mean \pm SEM. ${ }^{*} p<0.05,{ }^{* *} p<0.01,{ }^{* * *} p<0.001$ indicate significant difference. $C$ control group, $F_{2}$ 12-week fructose-fed group, S SCFAs-treated group, P pioglitazone-treated group

PPAR- $\gamma$ and its target gene (ANGPTL4) was downregulated in fructose-fed mice, which were restored by SCFAs and pioglitazone (Additional file 1: Figure S4b and c).

In the colons of normal mice, oral administration of SCFAs upregulated NLRP6 expression and increased IL-
18 production (Additional file 1: Figure S4d). In an ex vivo system of cultured mouse colonic explants (ex vivo colonic explants), SCFAs also increased NLRP6 expression and cleaved caspase-1 P10 protein levels and promoted IL-18 production, and these effects were suppressed by 

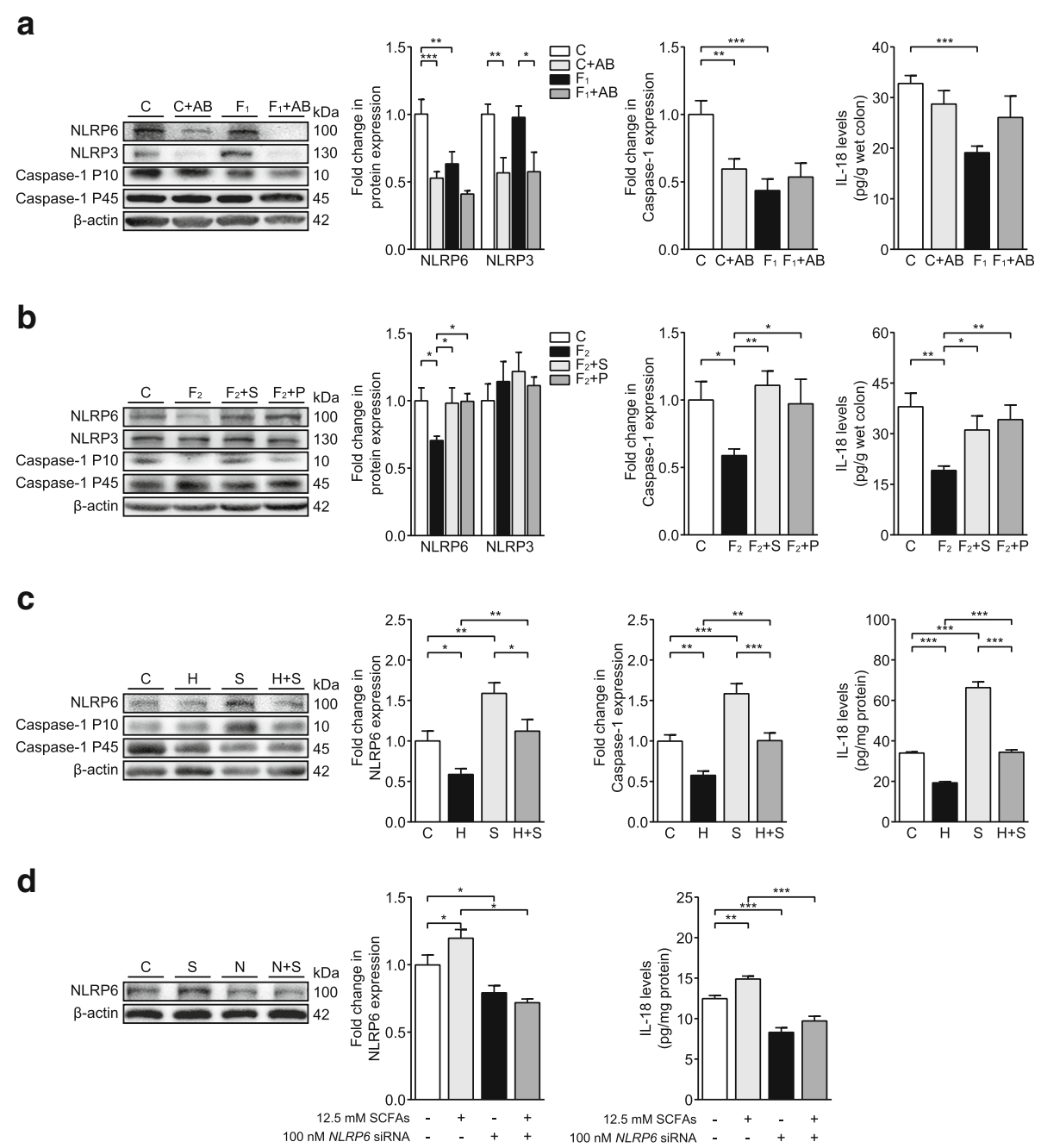

Fig. 4 A high-fructose diet causes colonic NLRP6 inflammasome dysfunction in C57BL/6N mice, which is ameliorated by SCFAs. Immunoblot analysis of NLRP6, NLRP3, and caspase-1 P10/P45 and IL-18 production $(\mathbf{a}, \mathbf{b})$ in colonic tissues of mice $(n=6)$, c cultured ex vivo colonic explants $(n=6)$, and $\mathbf{d}$ cultured mouse colon CT26 cells from three independent experiments. Data are presented as mean \pm SEM. ${ }^{*} p<0.05$, ${ }^{* *} p<0.01$, ${ }^{* * *} p<0.001$ indicate significant difference. C control group, $F_{1}$ eight-week fructose-fed group, $F_{2}$ 12-week fructose-fed group, AB antibioticstreated group, S SCFAs-treated group, P pioglitazone-treated group, H histamine-treated group, G GW9662-treated group

histamine (a bacterial metabolite) (Fig. 4c). Additionally, NLRP6 protein levels and IL-18 production were increased by SCFAs but decreased by NLRP6 siRNAs in murine CT26 colon carcinoma cells (Fig. 4d). However, neither pioglitazone nor GW9662 (a PPAR- $\gamma$ antagonist) affected basal or SCFAs-stimulated NLRP6 inflammasome activation in the ex vivo colonic explants (Additional file 1: Figure S4e). These results suggest that SCFAs may activate the NLRP6 inflammasome independently of PPAR- $\gamma$ activation.

\section{SCFAs and pioglitazone suppress the hippocampal neuroinflammatory response and neuronal loss in fructose-fed mice}

We confirmed that oral treatment with SCFAs significantly reduced IL- $1 \beta$, TNF- $\alpha$, and IL- 6 mRNA levels and the numbers of Iba- $1^{+}$microglia in the hippocampus of fructose-fed mice (Fig. 5a, b and Additional file 1: Figure S5a). SCFAs clearly increased the numbers of $\mathrm{DCX}^{+}$newborn neurons and $\mathrm{NeuN}^{+}$neurons (Fig. $5 \mathrm{~b}$ ) but could not inhibit the increase in the numbers of $\mathrm{GFAP}^{+}$astrocytes in the DG of the hippocampus in fructose-fed mice (Fig. 5b). More interestingly, SCFAs significantly increased the numbers of $\mathrm{DCX}^{+}$newborn neurons in the DG of the hippocampus in control mice (Additional file 1: Figure S5c). Similarly, pioglitazone significantly decreased IL-1 $\beta$, TNF- $\alpha$, and IL- 6 mRNA levels and the numbers of Iba- $1^{+}$ microglia in the hippocampus of fructose-fed mice (Fig. 5a, $\mathrm{b}$ and Additional file 1: Figure S5a). Moreover, pioglitazone clearly increased the numbers of $\mathrm{DCX}^{+}$newborn neurons and $\mathrm{NeuN}^{+}$neurons in hippocampal DG in fructose-fed mice (Fig. 5b). The numbers of newborn 


\section{a}
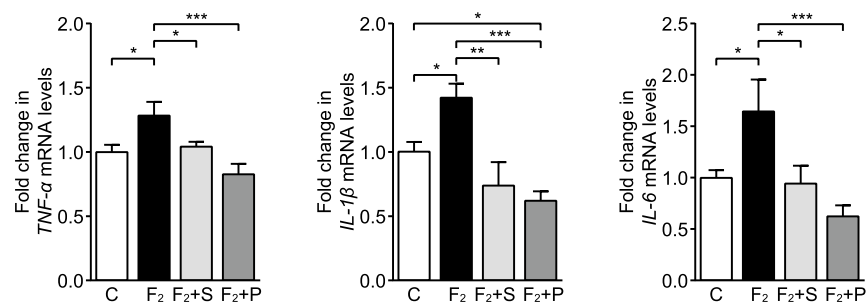

b

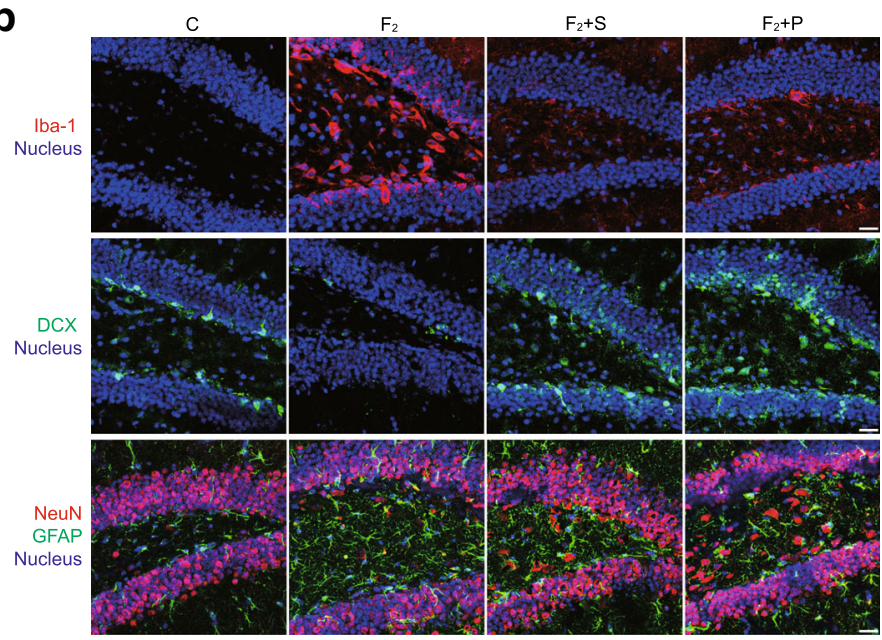
$\mathrm{F}_{2}+\mathrm{S}$ $\mathrm{F}_{2}+\mathrm{P}$
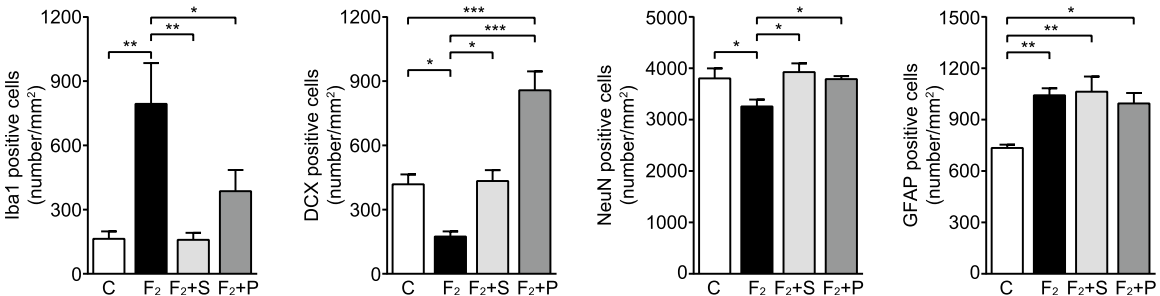

Fig. 5 SCFAs and pioglitazone inhibit hippocampal neuroinflammation and protect against neuronal loss in high-fructose diet-fed C57BL/6N mice. a TNF-a, IL-1 $\beta$, and IL-6 mRNA levels in the hippocampus $(n=6)$. b Representative immunofluorescence images and quantitative analysis of Iba-1-positive cells (red), DCX-positive cells (green), NeuN-positive cells (red), and GFAP-positive cells (green) with nuclear counterstain (blue) in the hippocampal DG. Bars, $25 \mu \mathrm{m}$. Data are presented as mean \pm SEM. ${ }^{*} p<0.05,{ }^{* *} p<0.01,{ }^{* *} p<0.001$ indicate significant difference. C control group, $F_{2}$ 12-week fructose-fed group, S SCFAs-treated group, P pioglitazone-treated group

neurons in fructose-fed mice treated with pioglitazone were even greater than that in control mice (Fig. 5b). Pioglitazone also failed to change the increase in the numbers of $\mathrm{GFAP}^{+}$astrocytes in the hippocampus of fructose-fed mice (Fig. 5b). There were no significant differences in the numbers of $\mathrm{GFAP}^{+}$astrocytes in the hippocampal CA1 and $\mathrm{CA} 3$ regions among fructose-fed mice treated or not treated with SCFAs and pioglitazone (Additional file 1: Figure S5b). These results suggest that SCFAs and pioglitazone can prevent neuronal injury by inhibiting neuroinflammation in fructose-fed mice.

\section{Discussion}

In the current study, we provided new experimental evidence for a critical role of a high-fructose diet-driven gut dysbiosis in the impairment of intestinal epithelial barrier that triggers hippocampal neuroinflammation and neuronal loss in mice. We found that C57BL/6N mice fed a highfructose diet for 8 or 12 weeks exhibited clear hippocampal neuroinflammatory response, and the activation and gliosis of microglia and astrocytes simultaneously caused significant reduction in the numbers of total and newborn neurons in hippocampal DG. The hippocampal DG is one of the few brain structures with high rates of neurogenesis. This brain structure is vulnerable to neuroinflammation, which causes neuronal loss and functional impairment [36]. Our findings demonstrated that a high-fructose diet induced early signs of neurodegeneration in hippocampus, representing a risk factor for the onset of neurodegenerative diseases [4]. Unexpectedly, fructose-fed C57BL/6N mice did not exhibit clear memory impairment in preliminary new objective recognition (NOR) and Morris water maze 
(MWM) tests, nor did they exhibit any changes in weight gain and insulin resistance compared with control mice (Additional file 1: Figure S6a-f). Previously, C57BL/6 mice fed with $15 \%$ fructose solution for eight weeks are reported to show spatial memory impairment in the MWM test [37]. Inconsistent with our findings, rats fed with $10 \%$ fructose solution for 28 weeks in a previous study show significantly reduced discrimination indices in the NOR test, whereas no spatial memory loss is observed in the MWM test in the fructose-fed group compared with the control group [38]. In another report, rats fed with a high-fructose diet (55\% kcal/g from fructose) for 10 weeks also show no spatial memory loss in the MWM test [39]. These conflicting results may be due to the differences in the amounts of fructose ingested and/or to different susceptibilities of the strains of animals used to the harmful effects of highfructose diets [40].

One of the most striking observations following broad-spectrum antibiotic treatment was the inhibition of hippocampal neuroinflammation and reactive gliosis in a high-fructose diet-fed group, which was similar to the action of antibiotics in a murine model of Alzheimer's disease, a progressive neurodegenerative disease [41]. We also found that the depletion of the gut microbiota caused a hippocampal neuronal loss in both the control and fructose-fed groups, suggesting the critical role of gut microbes and/or their metabolites in the modulation of hippocampal neurogenesis. Interestingly, SCFAs or the gut microbiota can restore defective microglia and reinforce the integrity of the blood-brain barrier in germ-free mice $[6,42]$. The beneficial effects of SCFAs on hippocampal neuroinflammation and neuronal loss in fructosefed animals further demonstrate the critical role of commensal microbes and/or their metabolites in the modulation of neurological function [7].

A critical objective was to determine whether a high-fructose diet could alter the gut microbial structure and SCFAs production in C57BL/6N mice. The changes at the phylum levels were consistent with a significantly lower relative abundance of Bacteroidetes and a significantly higher relative abundance of Proteobacteria in the fructose-fed group than in the control group [23]. Similar changes in the gut microbiota have been observed in humans and animals with inflammatory bowel disease [43] and neurodegeneration [44]. Increased Mucispirillum abundance is a signature of early disruption of the colonic surface mucus layer [45]. The increased abundance of pathogenic bacteria suggests the existence of infection and inflammation in fructose-fed C57BL/6N mice. Major SCFA-producing bacteria were highly enriched in fructose-fed animals in our study, while these bacteria were previously reduced in C57BL/6 J mice fed an $8 \%$ fructose solution for 12 weeks [46]. The contradictory findings may be due to the different genetic background of the animals. Additionally, our data demonstrated that fructose-driven gut dysbiosis contributed to intestinal epithelial barrier damage in C57BL/6N mice. Importantly, antibiotic-induced gut dysbiosis significantly reduced SCFAs production and downregulated colonic TJ expression in both control and fructose-fed groups. SCFAs exert protective effects on intestinal homeostasis and intestinal barrier function by modulating the inflammatory response against infectious bacteria in rodents $[47,48]$. SCFAs ameliorated fructose-induced damage to the intestinal epithelial barrier, resulting in the reduction of systemic endotoxin levels in C57BL/6N mice. These results further suggest that gut microbes and their metabolites are the crucial supports for intestinal epithelial barrier integrity, which may help to explain the inhibitory effects of SCFAs on hippocampal neuroinflammation and neuronal loss in high-fructose dietfed animals.

The NLRP6 inflammasome-derived IL-18 regulates colonic antimicrobial peptide expression [19] and maintains mucus layers [13, 15], orchestrating host defense against bacterial pathogens [49]. NLRP6-deficient C57BL/6 mice exhibit dramatic decreases in the diversity and richness of the gut microbiota but significant increase in Akkermansia muciniphila colonization [50]. Water-avoidance stress causes colonic NLRP6 inflammasome inhibition and small-bowel inflammation in C57BL/6 mice [51]. Like the NLRP6 inflammasome, the NLRP3 inflammasome is also involved in the innate immune system that discriminates pathogenic bacteria from commensal bacteria and shapes microbial ecology [52]. Here, the downregulation of colonic NLRP6 and NLRP3 expression was not completely consistent with the unchanged IL-18 production in antibiotic-treated C57BL/6N mice, indicating that additional inflammasomes, such as absent in melanoma 2 (AIM2) and/or NLRP4 [52], may be involved in sensing microbes and modulating the gut immune defense system in these animals. In addition, the activation of the colonic NLRP6 inflammasome, rather than the NLRP3 inflammasome, was disrupted, resulting in the reduction of colonic IL18 production in fructose-fed mice, which were consistent with the increase in pathogenic bacteria and the damage to the intestinal epithelial barrier. SCFA treatment attenuated the reduced NLRP6 and cleaved caspase-1 P10 expression as well as IL-18 production but exerted no impact on NLRP3 expression in fructosefed mice. SCFAs-induced NLRP6 inflammasome activation was suppressed by histamine in ex vivo colonic explants, and inhibited by NLRP6 siRNA in CT26 cells, demonstrating a direct regulation of the NLRP6 
inflammasome by SCFAs. These results suggest that in addition to the shaping of the microbial composition, the activation of the NLRP6 inflammasome may be another mechanism by which SCFAs protect against a high-fructose diet-induced intestinal epithelial barrier impairment in C57BL/6N mice.

Mechanistically, our results suggest that SCFAs could activate the normal or fructose-impaired NLRP6 inflammasome independently of PPAR- $\gamma$ activation. Host colonic epithelial PPAR- $\gamma$ is a direct target of SCFAs, which induce Angptl4 mRNA expression and protein secretion in colon cells by activating PPAR- $\gamma$ [53]. Consistent with the reduction in SCFAs, colonic PPAR- $\gamma$ protein and Angptl4 gene were downregulated in fructose-fed mice, which were restored by oral administration of SCFAs. PPAR- $\gamma$ agonist can prevent colonic NLRP6 inflammasome inhibition and intestinal disorder in water-avoidance stress-stimulated C57BL/6 mice [51]. Pioglitazone could improve defective colonic NLRP6 inflammasomes and protect against intestinal epithelial barrier impairment in fructose-fed mice, but it did not impact the activation of the NLRP6 inflammasome in ex vivo colonic explants. These observations suggest that pioglitazone may indirectly improve defective colonic NLRP6 inflammasome, possibly by modulating a high-fructose diet-induced gut dysbiosis, as we found in C57BL/6N mice. Moreover, pioglitazone was found to suppress the neuroinflammatory response and ameliorate neuronal loss in the hippocampus in fructose-fed animals. Pioglitazone has been reported to prevent Westernstyle diet-induced inflammatory reaction in adipose tissue as well as in the liver and brain in an animal model of obesity [27, 54, 55]. Therefore, pharmacological agents that are capable of preventing gut dysbiosis and the NLRP6 inflammasome dysfunction may have beneficial effects in attenuating a high-fructose diet-induced intestinal epithelial barrier damage and hippocampal neuroinflammation by potentially targeting PPAR- $\gamma$.

\section{Conclusions}

We have clearly shown that a high-fructose diet-induced aberrant structure of the gut microbiota and reduced fecal SCFAs levels, demonstrating a contribution of gut dysbiosis to hippocampal neuroinflammation in $\mathrm{C} 57 \mathrm{BL} / 6 \mathrm{~N}$ mice. Mechanistically, colonic NLRP6 inflammasome dysfunction was involved in intestinal epithelial barrier impairment, which was improved by SCFAs or pioglitazone. These results provide new evidence for the protective mechanisms of SCFAs and pioglitazone against hippocampal neuroinflammatory response and neuronal loss in this animal model. Our findings highlight the adverse impact of a feature of Western-style diets on hippocampal neuroinflammation and suggest a new intervention strategy for neurological dysfunction. However, more direct evidence should be obtained in the future.

\section{Materials and methods}

Animals and treatments

Four-week-old male C57BL/6N mice (17-20 g) raised under SPF conditions were purchased from the Beijing Vital River Laboratory Animal Technology Co., Ltd. (Beijing, China; production license: SCXK (Su) 20160003) and allowed to acclimatize to the animal facility environment for a week before being used for experimentation. They were housed in a specific pathogenfree, temperature- and humidity-controlled environment $\left(22 \pm 2{ }^{\circ} \mathrm{C}, 50 \pm 5 \%\right.$ humidity) with a standard $12 \mathrm{~h}$ light/dark cycle. These mice were given access to food and water ad libitum.

The mice were fed a standard diet (control group, 30 mice) or a high-fructose diet (fructose-fed group, 30 mice) with normal drinking water for four weeks firstly before any treatment in experiments I and II. The total calories were $3.4 \mathrm{kcal} / \mathrm{g}$ for the standard diet (rodent diet, XT002, Jiangsu Synergy Pharmaceutical Biological Engineering Co., Ltd., Nanjing, China) and $3.7 \mathrm{kcal} / \mathrm{g}$ for a high-fructose diet (35\% fructose-derived calories). The high-fructose diet was made with standard mouse chow by adding approximately $30 \%$ fructose according to a modified formula based on Choi's report [56]. Starting from the 4th week, the control and fructose-fed groups in experiments I and II were treated in a different way. In experiment I, half of the control and fructose-fed mice were treated orally with broad-spectrum antibiotics for the last four weeks according to Gacias' report [57]. The mice were given ampicillin $(1 \mathrm{~g} / \mathrm{L})$ in drinking water and a cocktail of vancomycin $(50 \mathrm{mg} / \mathrm{kg})$, neomycin $(100 \mathrm{mg} / \mathrm{kg})$, metronidazole $(100 \mathrm{mg} / \mathrm{kg})$, and amphotericin $B(1 \mathrm{mg} / \mathrm{kg})$ by gavage once daily. All antibiotics were obtained from Solarbio Science \& Technology Co., Ltd. (Beijing, China). In experiment II, fructose-fed mice were divided into three subgroups (15 mice/group) in the fourth week. Two groups were fed the high-fructose diet and simultaneously treated with SCFAs or pioglitazone (a PPAR- $\gamma$ agonist) for the last eight weeks according to our preliminary study, respectively. Another group continued to be fed the high-fructose diet for the last eight weeks. An admixture (3:1:1 ratio) of sodium acetate (S2889; Sigma-Aldrich Co., Ltd, Shanghai, China), sodium propionate (P1880; Sigma-Aldrich), and sodium butyrate (303410; Sigma-Aldrich) was incorporated into a high-fructose diet at a proportion of 5\% (wt/ $\mathrm{wt}$ ). A dose of $30 \mathrm{mg} / \mathrm{kg}$ pioglitazone was administered orally to the mice by gavage once a day. Body weight was recorded once a week throughout the experiment. 


\section{In vivo permeability assay}

Intestinal permeability was assessed with an in vivo FITCdextran (FD4; Sigma-Aldrich) permeability assay, as described previously [21]. Mice fasted for $4 \mathrm{~h}$ were gavaged with $0.6 \mathrm{mg} / \mathrm{g}$ body weight FITC-dextran $(4 \mathrm{kDa})$ in a 25 $\mathrm{mg} / \mathrm{mL}$ solution, and blood was collected by submandibular bleeding after $3 \mathrm{~h}$. The fluorescence intensity in serum was measured using a fluorescence spectrophotometer (Synergy 2, Biotek, Winooski, VT). FITC-dextran concentrations were determined from a standard curve generated with serial dilutions of FITC-dextran.

\section{Blood and tissue sample collection}

At the end of the experiments, the mice were fasted overnight and anesthetized with sodium pentobarbital $(50 \mathrm{mg} /$ $\mathrm{kg}$, i.p.), and blood was obtained by cardiopuncture. These blood samples were centrifuged at $2500 \mathrm{rpm}$ for $10 \mathrm{~min}$ to collect the serum samples, which were immediately frozen at $-80^{\circ} \mathrm{C}$ for biochemical assays. Hippocampus and colon tissues were dissected for histopathology, transmission electron microscopy (TEM) analysis, immunofluorescence staining, quantitative polymerase chain reaction (qPCR), and Western blot analysis.

\section{S rRNA gene sequence analyses}

Fresh stool samples from mice were collected in disinfected tubes, immediately frozen in liquid nitrogen upon collection, and stored at $-80^{\circ} \mathrm{C}$ until analysis. Stool DNA samples were isolated, and the microbiomes were analyzed at the Beijing Genomics Institute on an Illumina MiSeq platform. High-quality reads for bioinformatics analysis were selected, and all of the valid reads from all samples were clustered into operational taxonomic units (OTUs) based on $97 \%$ sequence similarity. $\alpha$-Diversity was calculated based on the Chao1 diversity index. The variation between the experimental groups ( $\beta$-diversity) was assessed with principal coordinate analysis (PCoA) plots. Linear discriminant analysis coupled with effect size (LEfSe) was performed with LEFSE software.

\section{Determination of fecal SCFAs concentrations}

SCFAs in the frozen fecal samples were determined by gas chromatography. The method used was adapted from that of Frost et al. [58]. Briefly, 150-200 mg of feces was combined with $550 \mu \mathrm{L}$ of PBS. These samples were vortexed thoroughly and centrifuged at $7200 \mathrm{rpm}$ for $10 \mathrm{~min}$, and the supernatant was collected. The SCFAs were extracted through the addition of $250 \mu \mathrm{L}$ of concentrated hydrochloric acid and $1 \mathrm{~mL}$ of diethyl ether followed by vortex mixing for $1 \mathrm{~min}$. The samples were centrifuged at 7200 rpm for $10 \mathrm{~min}$ after $12 \mathrm{~h}$, and the ether layer was transferred to a separate capped vial. Gas chromatography was performed on an HP 6890 Plus gas chromatograph equipped with a flame ionization detector, split/splitless injector, and an HP-INNOWax column (30 $\mathrm{m}$ length $\mathrm{x}$ $0.25 \mathrm{~mm}$ inner diameter, $0.25 \mu \mathrm{m}$ film thickness; Agilent Technologies, USA). The injector and detector temperatures were $300^{\circ} \mathrm{C}$, and the column temperature was programmed to increase from $80^{\circ} \mathrm{C}$ for 1 min to $150^{\circ} \mathrm{C}$ at $5^{\circ} \mathrm{C}$ per min. Nitrogen served as the carrier gas, and injections $(1 \mu \mathrm{L})$ were made in the split mode (10:1 split). The peak areas were recorded, and all subsequent data manipulation was completed using ChemStation Software (Agilent Technologies). Reference standards of acetic acid (A801295; Macklin), propionic acid (P816183; Macklin), and butyric acid (B802731; Macklin) were dissolved in diethyl ether to make the mixed stock solution. The concentrations of SCFAs were calculated by the standard curve method. The reported values were normalized according to the wet weight of the original fecal sample used.

\section{Ex vivo system of cultured mouse colonic explants}

An ex vivo system of cultured mouse colonic explants was constructed according to the methods in a previous report [13] (Additional file 2). Colons from eight-weekold normal C57BL/6N mice were longitudinally opened and washed thoroughly by flushing several times with cold HBSS containing $100 \mathrm{U} / \mathrm{mL}$ penicillin, $100 \mu \mathrm{g} / \mathrm{mL}$ streptomycin, and $50 \mu \mathrm{g} / \mathrm{mL}$ metronidazole. The colon tissues were cut into approximately $4-\mathrm{mm}^{2}$ fragments, placed on presoaked Gelfoam rafts, and cultured in 1 $\mathrm{mL}$ of RPMI 1640 medium containing 0.01\% BSA, 200 $\mathrm{U} / \mathrm{mL}$ penicillin, $200 \mu \mathrm{g} / \mathrm{mL}$ streptomycin, and $1 \%$ Fungizone. The colonic explants were incubated in the presence of a mixture (3:1:1 ratio) of sodium acetate, sodium propionate, and sodium butyrate with histamine (H7125; Sigma-Aldrich), pioglitazone, or GW9662 (a PPAR- $\gamma$ antagonist) for $24 \mathrm{~h}$ according to the experimental design. The culture medium and the colonic explants were collected to test the activation of the NLRP6 inflammasome and the transcription of PPAR- $\gamma$.

\section{Cell culture and treatment}

Murine CT26 colon carcinoma cells were purchased from the Shanghai Institutes for Biological Sciences (Shanghai, China) and grown in 1640 medium supplemented with $10 \%$ fetal bovine serum in a humidified atmosphere containing $5 \% \mathrm{CO}_{2}$ at $37^{\circ} \mathrm{C}$. For the experiments, cells were plated in 6-well plates for $12 \mathrm{~h}$ and transfected with NLRP6 siRNA or negative control siRNA (GenePharma, Shanghai, China) using Lipofectamine 2000 for $6 \mathrm{~h}$. These cells were then incubated in 1640 medium in the presence or absence of a $12.5 \mathrm{mM}$ mixture (3:1:1 ratio) of sodium acetate, sodium propionate, and sodium butyrate for $48 \mathrm{~h}$. The culture medium was collected, and the total cellular protein was extracted for biochemical and Western blot analysis. 


\section{qPCR analysis}

Hippocampus and colon tissues were isolated from the experimental mice and homogenized in TRIzol Reagent (Invitrogen), and total RNA was isolated according to the manufacturer's instructions. RNA $(1 \mu \mathrm{g})$ was reverse transcribed into complementary DNA using HiScript II Select qRT SuperMix (Vazyme, Nanjing, China). Quantitative polymerase chain reaction was performed using gene-specific primer sets and SYBR Green (Vazyme, Nanjing, China) on a real-time PCR detection system (Bio-Rad). The primer sequences used for amplification were as follows: mTNF- $\alpha \mathrm{F}\left(5^{\prime}-\mathrm{CCC}\right.$ CTT TAT TGT CTA CTC CTC-3'), mTNF- $\alpha \mathrm{R}$ (5'-CCC AGC ATC TTG TG TTT C-3'), mIL-1ßF (5'-ATT GTG GCT GTG GAG AAG-3'), mIL-1ßR (5'-AAG ATG AAG GAA AAG AAG GTG-3'), mIL-6F (5'-GCC TTC CCT ACT TCA CAA-3'), mIL-6R (5'-ACA ACT CTT TTC TCA TTT CCA C-3'), mPPAR- $\gamma$ F (5'-GTC TTG GAT GTC CTC GAT GGG-3'), mPPAR- $\gamma$ R (5'-TTA TGG AGC CTA AGT TTG AGT TTG C-3'), mAngplt4F (5'ATC TCC GAA GCC ATC CTT GTA-3'), mAngplt4R (5'-CTC TGG GGT CTC CAC CAT TTT-3'), m $\beta$ actinf (5'-CTC TCC CTC ACG CCA TC-3') and $m \beta-$ actinR (5'-ACG CAC GAT TTC CCT CTC-3'). All the primers were provided by GENEray Biotechnology (Shanghai, China). The reaction conditions were $94^{\circ} \mathrm{C}$ for $30 \mathrm{~s}$ followed by 40 cycles of $95^{\circ} \mathrm{C}$ for $5 \mathrm{~s}$ and $60^{\circ} \mathrm{C}$ for $30 \mathrm{~s}$. Relative expression was calculated using the $\Delta \Delta \mathrm{Ct}$ method with $\beta$-actin serving as the reference housekeeping gene. The expression of each target gene was normalized to $\beta$-actin expression, and the normalized data were presented as the fold change in gene expression in treated mice compared with control mice.

\section{Western blot analysis}

Colon tissues from experimental mice or cultured ex vivo colonic explants from normal mice were homogenized in ice-cold RIPA buffer containing protease inhibitors. The cleared lysates were obtained by centrifugation at 10,000 $\mathrm{rpm}$ at $4{ }^{\circ} \mathrm{C}$ for $15 \mathrm{~min}$. Protein quantification was carried out using a bicinchoninic acid (BCA) protein assay kit (Thermo Fisher Scientific, USA) with bovine serum albumin as a standard. Equivalent amounts of protein from each sample were separated by $10 \%$ SDS-PAGE and transferred onto polyvinylidene fluoride membranes (Millipore, USA). Subsequently, the membranes were blocked in 5\% milk, probed overnight at $4{ }^{\circ} \mathrm{C}$ with primary antibodies and then incubated with HRP-conjugated secondary antibodies. The primary antibodies included rabbit anti-Muc2 (ab76774, Abcam), rabbit anti-occludin (ab168986, Abcam), rabbit anti-ZO-1 (H-300, Santa Cruz), rabbit anti-NLRP6 (PA5-21022, Thermo Fisher Scientific), rabbit anti-caspase1 (sc-514, Santa Cruz), rabbit anti-NLRP3 (\#15101, CST), rabbit anti-PPAR- $\gamma(\# 2435$, CST), and mouse anti- $\beta$-actin
(\#4970, CST). The signals were detected with an enhanced chemiluminescence system (Tanon, Shanghai, China). The immunoreactive bands were quantified via densitometry using ImageJ (Version 1.50b, National Institutes of Health, USA) and standardized to $\beta$-actin and were expressed as fold changes relative to the control value.

\section{Ileal and colonic histopathology}

Excised ileum and colon tissues were fixed in 4\% paraformaldehyde and embedded in paraffin. The blocks were serially cut into 5 - $\mu \mathrm{m}$-thick sections and stained with hematoxylin and eosin (H\&E). Histological images were obtained using an Olympus IX53 microscope (Tokyo, Japan), an Olympus DP73 digital camera, and Olympus cellSens imaging software.

\section{Transmission electron microscopy (TEM) analysis}

Excised ileum and colon tissues were extensively washed of fecal matter and fixed in 2.5\% glutaraldehyde in PBS. For TEM, the tissue samples were processed with standard protocols at the Analysis Center of Nanjing Medical University (Nanjing, China) and examined using a JEOL JEM-1010 transmission electron microscope (Tokyo, Japan).

\section{Immunofluorescence staining and morphometric analysis} Three animals from each group were anesthetized and transcardially perfused with ice-cold $4 \%$ paraformaldehyde. The brains were excised, fixed in $4 \%$ paraformaldehyde overnight, incubated in $20 \%$ sucrose/PBS overnight at $4{ }^{\circ} \mathrm{C}$, and incubated in $30 \%$ sucrose/PBS overnight at $4{ }^{\circ} \mathrm{C}$. Then, the brain samples were frozen in optimum cutting temperature compound (Sakura Finetek, USA) and coronally cut with a cryostat into $30-\mu \mathrm{m}$-thick sections. The frozen sections were blocked with $10 \%$ fetal bovine serum in PBS for $1 \mathrm{~h}$ at room temperature. The slides were incubated with primary antibodies overnight at $4{ }^{\circ} \mathrm{C}$ and then incubated for $30 \mathrm{~min}$ at $37^{\circ} \mathrm{C}$ with Alexa Fluor-conjugated secondary antibodies (Invitrogen). The primary antibodies included mouse anti-Iba1 (sc-32725, Santa Cruz), mouse anti-NeuN (ab104224; Abcam), rabbit anti-DCX (ab77450; Abcam), and rabbit anti-GFAP (Z0334; Dako). The sections were counterstained with 4,6-diamidino-2-phenylindole (DAPI) for nuclear staining. Images were captured using a Leica TCS SP8 confocal microscope. Six randomly selected brain sections from each animal were used to outline and count immunofluorescence-positive cells in the hippocampal DG, CA1, and CA3 regions with Image-Pro Plus software (Media Cybernetics, USA).

\section{Statistical analysis}

Data are expressed as the mean \pm SEM. Statistical analyses were performed with GraphPad Prism Software 6.01 (GraphPad Software, San Diego, USA). Differences 
were analyzed by one-way analysis of variance (ANOVA) with post hoc tests for multiple group comparisons. $p$ values $<0.05$ were considered to indicate significance.

\section{Additional files}

Additional file 1: Figures S1-S6. Supplemental Figures. (DOCX 729 kb)

Additional file 2: Supplemental Methods. (DOCX $24 \mathrm{~kb}$ )

\section{Abbreviations}

AIM2: Absent in melanoma 2; DCX: Doublecortin; DG: Dentate gyrus;

DSS: Dextran sodium sulfate; IFN-ץ: Interferon gamma; LEfSe: Linear discriminant analysis coupled with effect size; Muc2: Mucin 2; MWM: Morris water maze; NOR: New objective recognition; OGTT: Oral glucose tolerance test; OTUs: Operational taxonomic units; PcoA: Principal coordinate analysis; PPAR-Y: Peroxisome proliferator-activated receptor gamma; SCFAs: Shortchain fatty acids; SPF: Specific pathogen-free; TEM: Transmission electron microscopy; TJs: Tight junction proteins; TNF-a: Tumor necrosis factor alpha; ZO-1: Zonula occludens-1; NLRP3/4/6: NLR family, pyrin domain-containing 3/4/6; IL-1B/6/10/18: Interleukin-1 beta/6/10/18; CA1/3: Cornu amonis 1/3; DAPI: 4,6-Diamidino-2-phenylindole

\section{Acknowledgements}

The authors thank Tu-Shuai Li, Han-Wen Yu, and Yun Gu for their big help in animal behavior study.

\section{Author's contributions}

LDK and JML conceived the project and designed experiments. RY, LPZ, SYW, and SJW contributed significantly to the experiments. JML, RY, and LDK performed the data analyses. XYZ and QX helped perform the analysis with constructive discussions. JML, LDK, and RY wrote and edited the manuscript. All authors read and approved the final manuscript.

\section{Funding}

This work was supported by National Natural Science Foundation of China (NSFC 81573476 and 81730105), National Natural Science Foundation of Jiangsu Province (BK20171346), and partly supported by the Fundamental Research Funds for the Central Universities.

\section{Availability of data and materials}

All 16S rRNA gene sequencing reads data has been deposited to the National Center for Biotechnology Information's Sequence Read Archive under accession number PRJNA540110.

\section{Ethics approval}

All experimental procedures were approved by the China Council on Animal Care at Nanjing University and the Institutional Animal Care and Use Committee at Nanjing University.

\section{Consent for publication}

Not applicable.

\section{Competing interests}

The authors declare that they have no competing interests.

Received: 5 October 2018 Accepted: 17 June 2019

Published online: 29 June 2019

\section{References}

1. Noble EE, Kanoski SE. Early life exposure to obesogenic diets and learning and memory dysfunction. Curr Opin Behav Sci. 2016;9:7-14.

2. Francis HM, Stevenson RJ. Higher reported saturated fat and refined sugar intake is associated with reduced hippocampal-dependent memory and sensitivity to interoceptive signals. Behav Neurosci. 2011;125:943-55.

3. Meng Q, Ying Z, Noble E, Zhao Y, Agrawal R, Mikhail A, et al. Systems nutrigenomics reveals brain gene networks linking metabolic and brain disorders. EBioMedicine. 2016;7:157-66.
4. Mastrocola R, Nigro D, Cento AS, Chiazza F, Collino M, Aragno M. Highfructose intake as risk factor for neurodegeneration: key role for carboxy methyllysine accumulation in mice hippocampal neurons. Neurobiol Dis. 2016;89:65-75.

5. Sharon G, Sampson TR, Geschwind DH, Mazmanian SK. The central nervous system and the gut microbiome. Cell. 2016;167:915-32.

6. Erny D, Hrabe de Angelis AL, Jaitin D, Wieghofer P, Staszewski O, David E, et al. Host microbiota constantly control maturation and function of microglia in the CNS. Nat Neurosci. 2015;18:965-77.

7. Frohlich EE, Farzi A, Mayerhofer R, Reichmann F, Jacan A, Wagner B, et al. Cognitive impairment by antibiotic-induced gut dysbiosis: analysis of gut microbiota-brain communication. Brain Behav Immun. 2016;56:140-55.

8. Rogers GB, Keating DJ, Young RL, Wong ML, Licinio J, Wesselingh S. From gut dysbiosis to altered brain function and mental illness: mechanisms and pathways. Mol Psychiatry. 2016;21:738-48.

9. Desai MS, Seekatz AM, Koropatkin NM, Kamada N, Hickey CA, Wolter M, et al. A dietary fiber-deprived gut microbiota degrades the colonic mucus barrier and enhances pathogen susceptibility. Cell. 2016;167: 1339-1353 e1321.

10. Mu Q, Kirby J, Reilly CM, Luo XM. Leaky gut as a danger signal for autoimmune diseases. Front Immunol. 2017:8:598.

11. Suzuki T. Regulation of intestinal epithelial permeability by tight junctions. Cell Mol Life Sci. 2013;70:631-59.

12. Marchiando AM, Shen L, Graham WV, Edelblum KL, Duckworth CA, Guan Y, et al. The epithelial barrier is maintained by in vivo tight junction expansion during pathologic intestinal epithelial shedding. Gastroenterology. 2011;140: 1208-18 e1201-1202.

13. Birchenough GM, Nystrom EE, Johansson ME, Hansson GC. A sentinel goblet cell guards the colonic crypt by triggering Nlrp6-dependent Muc2 secretion. Science. 2016;352:1535-42.

14. Elinav E, Strowig T, Kau AL, Henao-Mejia J, Thaiss CA, Booth CJ, et al. NLRP6 inflammasome regulates colonic microbial ecology and risk for colitis. Cell. 2011;145:745-57.

15. Wlodarska M, Thaiss CA, Nowarski R, Henao-Mejia J, Zhang JP, Brown EM, et al. NLRP6 inflammasome orchestrates the colonic host-microbial interface by regulating goblet cell mucus secretion. Cell. 2014;156:1045-59.

16. Round JL, Mazmanian SK. The gut microbiota shapes intestinal immune responses during health and disease. Nat Rev Immunol. 2009;9:313-23.

17. Ridaura VK, Faith JJ, Rey FE, Cheng J, Duncan AE, Kau AL, et al. Gut microbiota from twins discordant for obesity modulate metabolism in mice. Science. 2013;341:1241214.

18. Jakobsson HE, Rodriguez-Pineiro AM, Schutte A, Ermund A, Boysen P, Bemark $\mathrm{M}$, et al. The composition of the gut microbiota shapes the colon mucus barrier. EMBO Rep. 2015;16:164-77.

19. Levy M, Thaiss CA, Zeevi D, Dohnalova L, Zilberman-Schapira G, Mahdi $J A$, et al. Microbiota-modulated metabolites shape the intestinal microenvironment by regulating NLRP6 inflammasome signaling. Cell. 2015;163:1428-43.

20. Sellmann C, Priebs J, Landmann M, Degen C, Engstler AJ, Jin CJ, et al. Diets rich in fructose, fat or fructose and fat alter intestinal barrier function and lead to the development of nonalcoholic fatty liver disease over time. J Nutr Biochem. 2015;26:1183-92.

21. Rahman K, Desai C, Iyer SS, Thorn NE, Kumar P, Liu Y, et al. Loss of junctional adhesion molecule a promotes severe steatohepatitis in mice on a diet high in saturated fat, fructose, and cholesterol. Gastroenterology. 2016;151:733-46 e712.

22. ljssennagger N, Rijnierse A, de Wit NJ, Boekschoten MV, Dekker J, Schonewille A, et al. Dietary heme induces acute oxidative stress, but delayed cytotoxicity and compensatory hyperproliferation in mouse colon. Carcinogenesis. 2013;34:1628-35.

23. Do MH, Lee E, Oh MJ, Kim Y, Park HY. High-glucose or -fructose diet cause changes of the gut microbiota and metabolic disorders in mice without body weight change. Nutrients. 2018;10.

24. Volynets V, Louis S, Pretz D, Lang L, Ostaff MJ, Wehkamp J, et al. Intestinal barrier function and the gut microbiome are differentially affected in mice fed a western-style diet or drinking water supplemented with fructose. J Nutr. 2017;147:770-80

25. Agrawal R, Noble E, Vergnes L, Ying Z, Reue K, Gomez-Pinilla F. Dietary fructose aggravates the pathobiology of traumatic brain injury by influencing energy homeostasis and plasticity. J Cereb Blood Flow Metab. 2016;36:941-53. 
26. Hsu TM, Konanur VR, Taing L, Usui R, Kayser BD, Goran MI, et al. Effects of sucrose and high fructose corn syrup consumption on spatial memory function and hippocampal neuroinflammation in adolescent rats. Hippocampus. 2015;25:227-39.

27. Xu MX, Yu R, Shao LF, Zhang YX, Ge CX, Liu XM, et al. Up-regulated fractalkine (FKN) and its receptor CX3CR1 are involved in fructose-induced neuroinflammation: suppression by curcumin. Brain Behav Immun. 2016;58: 69-81.

28. Hung TV, Suzuki T. Dietary fermentable fiber reduces intestinal barrier defects and inflammation in colitic mice. J Nutr. 2016;146:1970-9.

29. Trompette A, Gollwitzer ES, Yadava K, Sichelstiel AK, Sprenger N, Ngom-Bru C, et al. Gut microbiota metabolism of dietary fiber influences allergic airway disease and hematopoiesis. Nat Med. 2014;20:159-66.

30. Lu Y, Fan C, Li P, Lu Y, Chang X, Qi K. Short chain fatty acids prevent highfat-diet-induced obesity in mice by regulating $\mathrm{G}$ protein-coupled receptors and gut microbiota. Sci Rep. 2016;6:37589

31. Zhou D, Pan Q, Xin FZ, Zhang RN, He CX, Chen GY, et al. Sodium butyrate attenuates high-fat diet-induced steatohepatitis in mice by improving gut microbiota and gastrointestinal barrier. World J Gastroenterol. 2017;23:60-75.

32. Sampson TR, Debelius JW, Thron $T$, Janssen $S$, Shastri GG, Ilhan ZE, et al. Gut microbiota regulate motor deficits and neuroinflammation in a model of Parkinson's disease. Cell. 2016;167:1469-1480 e1412.

33. Sun MF, Zhu YL, Zhou ZL, Jia XB, Xu YD, Yang Q, et al. Neuroprotective effects of fecal microbiota transplantation on MPTP-induced Parkinson's disease mice: Gut microbiota, glial reaction and TLR4/TNF-alpha signaling pathway. Brain Behav Immun. 2018;70:48-60.

34. Nepelska M, de Wouters T, Jacouton E, Beguet-Crespel F, Lapaque N, Dore J, et al. Commensal gut bacteria modulate phosphorylation-dependent PPARgamma transcriptional activity in human intestinal epithelial cells. Sci Rep. 2017;7:43199.

35. Byndloss MX, Olsan EE, Rivera-Chavez F, Tiffany CR, Cevallos SA, Lokken KL, et al. Microbiota-activated PPAR-gamma signaling inhibits dysbiotic Enterobacteriaceae expansion. Science. 2017;357:570-5.

36. Valero J, Bernardino L, Cardoso FL, Silva AP, Fontes-Ribeiro C, Ambrosio AF, et al. Impact of neuroinflammation on hippocampal neurogenesis: relevance to aging and Alzheimer's disease. J Alzheimers Dis. 2017;60:S161-8.

37. Cisternas $P$, Salazar $P$, Serrano FG, Montecinos-Oliva C, Arredondo SB, VarelaNallar $L$, et al. Fructose consumption reduces hippocampal synaptic plasticity underlying cognitive performance. Biochim Biophys Acta. 2015; 1852:2379-90.

38. Sanguesa G, Cascales M, Grinan C, Sanchez RM, Roglans N, Pallas M, et al. Impairment of novel object recognition memory and brain insulin signaling in fructose- but not glucose-drinking female rats. Mol Neurobiol. 2018;55: 6984-99.

39. Woodie L, Blythe S. The differential effects of high-fat and highfructose diets on physiology and behavior in male rats. Nutr Neurosci. 2018;21:328-36

40. Fontaine DA, Davis DB. Attention to background strain is essential for metabolic research: C57BL/6 and the International Knockout Mouse Consortium. Diabetes. 2016:65:25-33.

41. Minter MR, Zhang C, Leone V, Ringus DL, Zhang X, Oyler-Castrillo P, et al. Antibiotic-induced perturbations in gut microbial diversity influences neuroinflammation and amyloidosis in a murine model of Alzheimer's disease. Sci Rep. 2016;6:30028.

42. Braniste V, Al-Asmakh M, Kowal C, Anuar F, Abbaspour A, Toth M, et al. The gut microbiota influences blood-brain barrier permeability in mice. Sci Transl Med. 2014;6:263ra158.

43. Gophna U, Sommerfeld K, Gophna S, Doolittle WF, Veldhuyzen van Zanten SJ. Differences between tissue-associated intestinal microfloras of patients with Crohn's disease and ulcerative colitis. J Clin Microbiol. 2006;44:4136-41.

44. Tognini P. Gut microbiota: a potential regulator of neurodevelopment. Front Cell Neurosci. 2017;11:25

45. Belzer C, Gerber GK, Roeselers G, Delaney M, DuBois A, Liu Q, et al. Dynamics of the microbiota in response to host infection. PLoS One. 2014;9:e95534.

46. Ahn IS, Lang J, Ying ZHE, Byun HR, Zhang G, Olson C, et al. Host genetic background and gut microbiota contribute to differential metabolic responses to high fructose consumption in mice. Diabetes. 2018:67:290-LB.

47. Correa RO, Vieira A, Sernaglia EM, Lancellotti M, Vieira AT, Avila-Campos MJ, et al. Bacterial short-chain fatty acid metabolites modulate the inflammatory response against infectious bacteria. Cell Microbiol. 2017.
48. Tong LC, Wang Y, Wang ZB, Liu WY, Sun S, Li L, et al. Propionate ameliorates dextran sodium sulfate-Induced colitis by improving intestinal barrier function and reducing inflammation and oxidative stress. Front Pharmacol. 2016;7:253

49. Anand PK, Malireddi RK, Lukens JR, Vogel P, Bertin J, Lamkanfi M, et al. NLRP6 negatively regulates innate immunity and host defence against bacterial pathogens. Nature. 2012;488:389-93

50. Seregin SS, Golovchenko N, Schaf B, Chen J, Pudlo NA, Mitchell J, et al. NLRP6 protects II10-/- mice from colitis by limiting colonization of Akkermansia muciniphila. Cell Rep. 2017;19:2174.

51. Sun Y, Zhang M, Chen CC, Gillilland M 3rd, Sun X, El-Zaatari M, et al. Stressinduced corticotropin-releasing hormone-mediated NLRP6 inflammasome inhibition and transmissible enteritis in mice. Gastroenterology. 2013;144: 1478-87 1487 e1471-1478.

52. Bauernfeind F, Hornung V. Of inflammasomes and pathogens--sensing of microbes by the inflammasome. EMBO Mol Med. 2013;5:814-26.

53. Alex S, Lange K, Amolo T, Grinstead JS, Haakonsson AK, Szalowska E, et al. Short-chain fatty acids stimulate angiopoietin-like 4 synthesis in human colon adenocarcinoma cells by activating peroxisome proliferator-activated receptor gamma. Mol Cell Biol. 2013;33:1303-16.

54. Kim MS, Yamamoto Y, Kim K, Kamei N, Shimada T, Liu L, et al. Regulation of diet-induced adipose tissue and systemic inflammation by salicylates and pioglitazone. PLoS One. 2013;8:e82847.

55. Collino M, Aragno M, Castiglia S, Miglio G, Tomasinelli C, Boccuzzi G, et al. Pioglitazone improves lipid and insulin levels in overweight rats on a high cholesterol and fructose diet by decreasing hepatic inflammation. $\mathrm{Br} \mathrm{J}$ Pharmacol. 2010;160:1892-902.

56. Choi $Y$, Abdelmegeed MA, Song BJ. Diet high in fructose promotes liver steatosis and hepatocyte apoptosis in C57BL/6 J female mice: role of disturbed lipid homeostasis and increased oxidative stress. Food Chem Toxicol. 2017;103:111-21

57. Gacias M, Gaspari S, Santos PM, Tamburini S, Andrade M, Zhang F, et al. Microbiota-driven transcriptional changes in prefrontal cortex override genetic differences in social behavior. Elife. 2016;5.

58. Frost G, Sleeth ML, Sahuri-Arisoylu M, Lizarbe B, Cerdan S, Brody L, et al. The short-chain fatty acid acetate reduces appetite via a central homeostatic mechanism. Nat Commun. 2014:5:3611.

\section{Publisher's Note}

Springer Nature remains neutral with regard to jurisdictional claims in published maps and institutional affiliations.

Ready to submit your research? Choose BMC and benefit from:

- fast, convenient online submission

- thorough peer review by experienced researchers in your field

- rapid publication on acceptance

- support for research data, including large and complex data types

- gold Open Access which fosters wider collaboration and increased citations

- maximum visibility for your research: over $100 \mathrm{M}$ website views per year

At $\mathrm{BMC}$, research is always in progress.

Learn more biomedcentral.com/submission 